Spatial HAC estimator: analysis of convergence of European regions

Oleksandr Shepotylo (Kyiv School of Economics and Kyiv Economics Institute) 


\title{
Spatial HAC estimator: analysis of convergence of European regions
}

\author{
Oleksandr Shepotylo* \\ Kyiv School of Economics and Kyiv Economics Institute
}

November 2008

\begin{abstract}
This paper applies a nonparametric heteroskedasticity and autocorrelation consistent (HAC) estimator of error terms in the context of the spatial autoregressive model of GDP per capita convergence of European regions at NUTS 2 level. By introducing the spatial dimension, it looks at how the equilibrium distribution of GDP per capita of EU regions evolves both in time and space dimensions. Results demonstrate that the global spatial spillovers of growth rates make an important contribution to the process of convergence by reinforcing the economic growth of neighboring regions. Results are even more pronounced when the convergence in wage per worker is considered. The choice of kernel functions does not significantly affect the estimation of the variance-covariance matrix, while the choice of the bandwidth parameter is quite important. Finally, results are sensitive to the weighting matrix specification, and further research is needed to give a more rigorous justification for the selection of the weighting matrix.
\end{abstract}

JEL categories:

Keywords: convergence, spatial econometrics, regional economics, EU

*Email: oshepotylo@eerc.kiev.ua. 


\section{Introduction}

Traditional models of income convergence across countries (Mankiw et al., 1992) or regions within a country (Barro and Sala-i-Martin, 1992) concentrate on the time dimension, but they ignore the space dimension of convergence. They look at units of analyses isolated from each other in space as if they were remote islands. For this assumption to be true, we should not expect systematic differences in the growth rates of different regions of the world. However, empirical evidence suggests that different parts of the world grow at different speeds and growth rates are spatially correlated. Can those differences be explained by a more favorable, absolute geographical location that provides an advantage to some regions? Are there large positive spillovers that speed up and reinforce the growth of geographically close regions? Finally, do spatial links between regions change the results of analyses that study the time dynamics of convergence? This paper tries to answer these important questions in the context of the spatial autoregressive model of income per capita convergence of European regions at NUTS 2 level. By introducing the spatial dimension, we can look at how the equilibrium distribution of GDP per capita of EU regions evolves in both time and space.

Recent advances in spatial statistics point to shortcomings in the traditional approach of modeling convergence as a purely time dynamic process and directly introduce the spatial dimension by modeling spatial interactions in explanatory variables and error terms. However, spatial models typically assume a very specific error structure that frequently includes a spatial autoregressive error parameter and a homoskedastic innovation term. This error structure produces the estimation of the variance-covariance matrix, which is not robust when innovations are heteroskedastic and spatially correlated in a nontrivial manner, and, as a result, the corresponding variance-covariance matrix is not estimated correctly. Specifically, the assumption of homoskedastic errors is not a good approximation to model spatial correlations across geographical regions that differ in size and other important characteristics. In addition, the assumption of no spatial correlation in the error term is violated if the estimated model has omitted variables that are spatially correlated. To provide a robust estimation of the standard errors of the estimated coefficients, this paper applies a nonparametric heteroskedasticity and autocorrelation consistent (HAC) estimator of error terms, as suggested by Kelejian and Prucha (2007)

The rest of the paper is organized as follows. First, I explain why spatial links between regions are important. Second, I discuss factors that lead to spatially correlated and heteroskedastic errors. Third, I set up a model of regional growth that includes a possibility of spatial spillovers across regions. Fourth, I explain the estimation technique focusing on the robust estimation of the error 
term. Fifth, I describe the data and present summary statistics. Finally, I present results and discuss the direction further research should take.

\section{Spatial Dependence}

The study of economic development and convergence across countries or regions within a country constantly draws the attention of economic researchers. In a seminal paper, Mankiw et al. (1992) demonstrated that according to the Solow growth model countries located further away from their steady-state equilibrium should converge faster than countries that are closer to the steady state. They found convergence across countries by showing that relatively poor countries grew faster then relatively rich ones over the period 1960-1985. The Solow growth model and its predictions were also tested with regional data. For example, Barro and Sala-i-Martin (1992) found that the states in the U.S. converged during 1840-1988 and estimated the speed of convergence at 2 percent per year. However, those studies ignore the possibility of the spatial dependence in the cross-country regression and treat each unit of observation as an isolated island.

The spatial dependence across regions can emerge due to economic spillovers that reflect the mobility of goods and factors of production, the spread of knowledge and technology, as well as the interdependence of institutions. For example, the new economic geography theory explicitly introduces the market potential and supplier's access - factors that are interregional by nature - as two of the major reasons for the agglomeration of firms (Head and Mayer, 2004; Amiti and Javorcik, 2008) that drive decisions of multinationals to invest in a particular region. Durlauf and Quah (1999) discuss the possibility of spatial interdependence in the context of the growth model with human capital spillovers across countries (initially introduced by Lucas, 1993) and point out that these spillovers markedly change the dynamics of convergence and necessitate the modeling of cross-country interactions in any empirical analysis. A country's institutional arrangements have a very strong impact on the level of GDP per capita, and they are influenced by changes in the institutional quality in neighboring countries. Kelejian et al. (2007) demonstrate that the quality of governance largely is determined by the quality of governance in neighboring countries due to economic and political factors that include political instability, armed conflicts, and copycat policies. Ades and Chua (1997) find that regional instability (average number of coups and revolutions in neighboring countries) has a negative effect on growth. Finally, as noted by DeLong and Summers (1991), any important omitted variables that are similar in neighboring countries can generate spatially correlated error terms in cross-country growth regressions (i.e., contagion effect, regional business cycles, and impact of common currency). 
The spatial interactions are even more pronounced for regions within a country because of lower barriers to trade and migration and similarities of neighboring regions within a country in terms of institutional and cultural characteristics. An increasing number of studies recognize the importance of modeling spatial dependence within the framework of regional development models. Abreu et al. (2004) present a review of the literature on growth and convergence, focusing on spatial factors, and point out that the number of papers on the topic has grown significantly since 1997. To name a few, Rey and Montouri (1999) investigated the spatial dependence across the U.S. and found evidence of positive spatial autocorrelation for state-level personal income. Garret et al. (2005) studied spatial autocorrelation in growth rates across the U.S. and found that a one percentage point increase in the average income growth of neighboring states generated a 0.23 percentage point increase in a state's growth rate. A number of studies looked at the convergence of European regions and found evidence of spatial dependence (Fingleton, 2001; Baumont et al., 2003; Le Gallo, 2004; Lopez-Bazo et al., 2004; Arbia et al., 2005). The focus on European regions allows us to look at the convergence process of regions with a high variability in economic, institutional, and cultural characteristics that were recently unified within the European Union.

This paper differs from other studies of convergence in several important ways. First, the model allows for the possibility of spatial spillovers both in the dependent variable and in the error term and offers an estimation procedure that is consistent under a wide class of models with spatial dependence. Because some of the spatial effects are not observable, it is extremely important to use the estimation methodology that is robust to arbitrary spatial correlation in the error structure. In general, studies of regional convergence either ignore the spatial correlation in the error term or impose a specific error structure (i.e., spatial autoregressive process in the error term). I apply a nonparametric heteroskedasticity and autocorrelation consistent (HAC) estimator (Kelejian and Prucha, 2007) within a framework of the spatial autoregressive model that includes global spatial spillovers in the dependent variable.

Second, the paper looks at a geographically extended sample of EU-25 regions at NUTS 2 levels of aggregation for the period 1999-2005. This provides more variation in the measure of economic development. Further, it allows us to examine whether including newly accepted regions, which were considerably less developed in 1999 and experienced a significant transformation during the investigated period, significantly influences the results. 


\section{Heteroskedasticity and Unobservable Spatial Autocorrelation}

Conceptually, any omitted variable that is spatially correlated with some of the explanatory variables leads to a violation of the assumption of spatial independence of errors. DeLong and Summers (1991) point out that any important omitted variables that are similar in neighboring countries should generate spatially correlated error terms in cross-country growth regressions (i.e., contagion effect, regional business cycles, and impact of common currency). It is important to address this issue directly because a violation of the spatial independence of errors assumption leads to an inconsistent estimation of the variance covariance matrix that in turn leads to incorrectly estimated confidence intervals of the model coefficients.

To illustrate the last point, consider the following examples. First, accession of new member states to the EU leads to a more open trade regime for the Eastern European regions and more labor market opportunities for Eastern European labor migrants. The impact of the accession of new members on the economic development of all EU regions, however, is not uniform and varies depending on the geographical configuration and relative locations of the regions. Second, in the empirical part, I look at the European regions as if they were parts of a closed economy that does not interact with other regions located outside of the EU, which is a very common approach in the regional studies. However, depending on the location of each particular region in the EU, this assumption is not always a good approximation of reality. Consider, for example, the impact of a shock coming from higher energy prices imported from Russia on economic growth in the EU regions. It affects the countries that are closer to Russia and depend more on Russian supplies of oil and gas. Therefore, the omitted impact of the energy price shock on economic growth is spatially dependent, which clearly violates the error independence assumption of a standard spatial model.

To formalize the last point, consider a spatial model $y=\rho W y+X \beta+\varepsilon$, where $y$ is a vector of observations on the dependent variable for all regions in the world, $X$ is a matrix of exogenous explanatory variables, $W$ is an exogenous matrix of spatial weights, and $\varepsilon$ is a vector of $\operatorname{iid}\left(0, \sigma^{2}\right)$ errors.

Consider a partition of the spatial matrix that describes the relationship between all regions in the world into the submatrix of spatial interactions of the European regions with other European regions, $W_{11}$, and the submatrix of spatial interactions of the European regions with the rest of the world, $W_{12}$. I similarly split the dependent variable $y=\left(y_{1}^{\prime}, y_{2}^{\prime}\right)^{\prime}$, explanatory variables $X=\left(X_{1}^{\prime}, X_{2}^{\prime}\right)^{\prime}$, and the error term $\varepsilon=\left(\varepsilon_{1}^{\prime}, \varepsilon_{2}^{\prime}\right)^{\prime}$. The estimated relationship for the sample of European regions is described as: 


$$
y_{1}=\rho W_{11} y_{1}+X_{1} \beta+\rho W_{12} y_{2}+\varepsilon_{1}=\rho W_{11} y_{1}+X_{1} \beta+u_{1}
$$

where $u_{1}=\rho W_{12} y_{2}+\varepsilon_{1}$. Clearly, the omitted spatial interactions produce errors that are heteroskedastic and spatially correlated.

Although in the two examples presented in this section I can deal with particular types of omitted variables by directly including them in the estimated equation, the list of possible omitted effects is not exhausted by the mentioned examples and can be continued. Therefore, estimation of the model using the robust method suggested in the paper offers a more tractable solution.

\section{$4 \quad$ Production and Spatial Spillovers}

Following Mankiw et al. (1992), let the production function of a region $i$ at time $t$ be:

$$
Y_{i t}=B_{i t} K_{t}^{\alpha} H_{t}^{\beta}\left(A_{t} L_{t}\right)^{1-\alpha-\beta}
$$

where $Y$ is output, $K$ is the stock of physical capital, $H$ is the stock of human capital, $A$ is the level of technology, $L$ is labor, and $B$ is the total factor productivity. Labor and technology grow exogenously:

$$
\begin{aligned}
& L_{t}=L_{0} \exp (n t) \\
& A_{t}=A_{0} \exp (g t)
\end{aligned}
$$

$B_{i t}$ depends on the spatial location of the region and is the primary interest of this paper. I postulate that the total factor productivity of the region $i$ positively depends on the GDP per capita of the neighboring regions through spillovers in the market potential and supplier access. The international trade theory provides ample support for this claim in at least two important ways. First, stylized facts show that exporting and multinational enterprises (MNE) are more productive then domestic firms (e.g., Bernard and Jensen, 1999). Moreover, Helpman et al. (2004) developed a theoretical model that, among other things, predicts that multinational firms are the most productive. At the same time, the literature on MNEs locations stresses the importance of the market potential as one of the major reasons for investing in a particular region (e.g., Head and Mayer, 2004). Therefore, other things being equal, the fact that regions with more developed neighbors attract more productive firms increases the average productivity of the region. Second, regions that have more developed neighbors enjoy a wider choice 
of intermediate goods suppliers that can be used as inputs in the production process. This, in turn, lowers production costs and increases the productivity of firms located in the region (Amiti and Javorcik, 2008).

In the next section, the spatial spillovers are introduced in the framework of the Solow growth model.

\subsection{Convergence}

The Solow model predicts that income per capita of region $i$ converges to the steady-state value for the region and the rate of convergence is proportionate to the deviation of the current level of GDP per capita from the steady-state level. Approximating around the steady state, the rate of convergence is:

$\ln y_{i t}-\ln y_{i t-1}=\lambda\left(\ln y^{*}-\ln y_{i t-1}\right)$

where $y_{i t}$ is GDP per capita in region $i$ at time $t, y^{*}$ is the steady-state GDP per capita, and

$$
\lambda=(n+g+\delta)(1-\alpha-\beta)
$$

Plugging the expression for the steady-state level of GDP per capita, equation (2) can be transformed as follows:

$\ln y_{i t}-\ln y_{i t-1}=\ln B_{i t}+\gamma_{1} \ln s_{i t}^{k}+\gamma_{2} \ln s_{i t}^{h}-\gamma_{3} \ln \left(n_{i t}+g+\delta\right)-\gamma_{4} \ln y_{i t-1}$

where $y_{i t}$ is GDP per capita in region $i$ at time $t, s_{i t}^{k}$ and $s_{i t}^{h}$ are investments in physical and human capital to GDP ratios, $n_{i t}$ is the population growth, $g$ is an exogenous technological improvement, and $\delta$ is the capital depreciation rate, which is assumed to be equal for physical and human capital.

\subsection{Parameterization of $\ln B_{i t}$}

To model the regional interdependence, equation (3) is augmented by including a weighted average of the growth rates in GDP per capita of the neighboring regions, $\sum_{j, j \neq i} w_{i j}\left(\ln y_{j t}-\ln y_{j t-1}\right)$, which is called the spatial lag of the dependent variable in the spatial econometrics literature (e.g., Anselin, 1988). It captures the global spatial spillovers without explicitly specifying the channels through which 
such spillovers spread from one region to another. I assume the following functional form for the log of total factor productivity:

$$
\ln B_{i t}=\rho \sum_{j, j \neq i} w_{i j}\left(\ln y_{j t}-\ln y_{j t-1}\right)+u_{i t}
$$

The choice of appropriate weights poses a serious problem because they should be exogenous, known ex ante, and cannot be estimated within the model. ${ }^{1}$ For the baseline model specification, I select weights that are inversely related to distance between regions $i$ and $j$ and normalized by each row to add up to one:

$$
\begin{aligned}
& w_{i j}=\frac{1 / d_{i j}}{\sum_{j=1, j \neq i}^{N} 1 / d_{i j}} \text { if } i \neq j \\
& w_{i i}=0
\end{aligned}
$$

Under the assumption of no spatial interdependence, the coefficient $\rho$ of the spatial lag is equal to zero and can be tested using the standard Wald test. $u_{i t}$ is the error term, which is allowed to be heteroskedastic and spatially correlated across regions. I elaborate on the structure of the error term and estimation of the variance-covariance structure in the next section.

\section{Estimation}

\subsection{SLS and HAC Robust Standard Errors}

Using expression $\rho \sum_{j, j \neq i} w_{i j}\left(\ln y_{j t}-\ln y_{j t-1}\right)+u_{i t}$ for $\ln B_{i t}$, equation (3) can be rewritten as:

$$
\begin{aligned}
\ln y_{i t}-\ln y_{i t-1} & =\rho \sum_{j, j \neq i} w_{i j}\left(\ln y_{j t}-\ln y_{j t-1}\right)+\gamma_{1} \ln s_{i t}^{k}+\gamma_{2} \ln s_{i t}^{h} \\
& -\gamma_{3} \ln \left(n_{i t}+g+\delta\right)-\gamma_{4} \ln y_{i t-1}+u_{i t}
\end{aligned}
$$

or using the matrix notation:

${ }^{1}$ Estimation of weights within the model tends to bias the resulting estimated matrix towards a matrix with equal off-diagonal elements. 
$Y_{t}=X_{t} \beta+\rho W Y_{t}+u_{t}=Z_{t} \delta+u_{t}, t=1,2, \ldots, T$

where $Y_{t}=\left(\ln y_{1 t}-\ln y_{1 t-1}, \ln y_{2 t}-\ln y_{2 t-1}, \ldots, \ln y_{N t}-\ln y_{N t-1}\right)^{\prime}$ is the vector of observations of the dependent variable at time $t, X_{t}$ is the matrix of explanatory variables at time $t, u_{t}$ is the vector of errors, and $W$ is the $\mathrm{NxN}$ weighting matrix. $u$ is generated according to the following process:

$u_{t}=R \varepsilon_{t}$

where $\varepsilon_{t}$ is an $\mathrm{Nx} 1$ vector of innovations and $R$ is an $\mathrm{NxN}$ nonstochastic matrix whose elements are not known. $\varepsilon_{i}$ is i.i.d. $(0,1)$ with $E\left|\varepsilon_{i}\right|^{q} \leq c_{E}$ for some $q \geq 4$ and $0<c_{E}<\infty$.

The spatial lag of the regional growth rates, $W Y$, is an endogenous variable and cannot be estimated by simple OLS regression (Kelejian and Prucha, 1999). However, the model equation (5) can be estimated by the instrumental variable technique that uses spatial lags of exogenous variables as instruments. The spatial 2SLS estimator has the following form: ${ }^{2}$

$$
\hat{\delta}=\left(\hat{Z}^{\prime} Z\right)^{-1} \hat{Z}^{\prime} y
$$

The asymptotic distribution of $\hat{\delta}$ involves $\Psi=\left(\psi_{i j}\right)=V C\left(n^{-1 / 2} H^{\prime} u\right)=n^{-1} H^{\prime} \Sigma H$ where $H=\left[X, W X, W^{2} X\right]$ and $\Sigma=\left(\sigma_{i j}\right)=E u u^{\prime}$. Let $\hat{u}=y-Z \hat{\delta}$ and $\hat{\Psi}$ be the SHAC estimator of $\Psi$. As shown by Kelejian and Prucha (2007), the elements of $\hat{\Psi}$ can be computed as:

$$
\hat{\Psi}_{r, s}=n^{-1} \sum_{i=1}^{n} \sum_{j=1}^{n} h_{i r} h_{j s} \hat{u}_{i} \hat{u}_{j} K\left(d_{i j} / d^{*}\right)
$$

where the kernel function $K: R \rightarrow[-1,1]$ with $K(0)=1, K(x)=K(-x), K(x)=0$ for $|x|>1$, satisfies $|K(x)-1| \leq c_{K}|x|^{\rho},|x|<1$, for some $\rho \geq 1$ and $0<c_{K}<\infty$.

\footnotetext{
${ }^{2}$ See the Appendix for a detailed discussion of the selection of instruments and the 2SLS
} estimation procedure. 


\subsection{Choice of the Bandwidth and Kernel Function}

I consider three kernel functions, $K(x)$, that satisfy the criteria mentioned in the previous section. The Bartlett and Parzen kernels for HAC estimation proposed by Newey and West (1987) and Gallant (1987, p. 533) consequently satisfy the assumptions required for the kernel $K(x)$ and generate a positive semidefinite estimator of $\hat{\Psi}$. In addition, I report results for the Tukey-Hanning kernel, which is frequently used in the literature (Andrews, 1991) and produces a positive semidefinite estimation of $\hat{\Psi}$. In the application that I consider, different kernel functions produce similar estimates of $\hat{\Psi}$, which is consistent with the findings from the nonparametric literature (Mittelhammer et al., 2000).

The choice of the bandwidth, on the other hand, is more important for consistency because the estimation of the elements of $\hat{\Psi}$ is quite sensitive to the choice of the bandwidth. Kelejian and Prucha (2007) recommend computing the bandwidth parameter based on the following condition:

$$
l_{n}=o_{p}\left(n^{\tau}\right)
$$

where $l_{n}=\max \left(l_{1 n}, l_{2 n}, \ldots, l_{i n}, \ldots l_{n n}\right), l_{i n}$ is the number of regions for which the distance between region $i$ and all other regions is less than or equal to $d^{*}$, and $\tau \leq 1 / 2(q-2) /(q-1)$. By assumption, $q \geq 4$, which gives the upper limit on $\tau \leq 1 / 2$.

Lambert et al., (2008), on the other hand, found that in applied work it is advisable to consider higher values of $\tau$ as well to get a more conservative estimation of the variance-covariance matrix. In particular, they found that $\tau=2 / 3$ or, in some circumstances, $\tau=3 / 4$ are plausible values in their estimated sample. In the empirical part, I present the results for several values of $\tau$ to study the sensitivity of the estimation to the choice of the bandwidth parameter $l_{n}$.

\section{$6 \quad$ First Look at the Data}

The main data source is the Regional Statistics published by Eurostat. Specifically, I use nominal regional gross domestic product for 1999-2005 at NUTS 2 level and population data for the same period to calculate nominal regional GDP per capita. ${ }^{3}$ The gross-fixed-capital formation in current Euros and

\footnotetext{
${ }^{3}$ I can go back in time as far as 1995 , but at the cost of losing 20 percent of our sample.
} 
the number of tertiary education employees ${ }^{4}$ in the region are used to construct proxies for $s_{k}$ and $\mathrm{s}_{\mathrm{h}}$.

I construct a cross section of 201 regions for which the data on all relevant variables are available. Initial conditions are captured by the log of GDP per capita in 1999. I take the period average of investment to GDP ratio and the period average share of employees with a tertiary level of education in the total employment population to measure $s_{k}$ and $\mathrm{s}_{\mathrm{h}}$ consequently. Finally, I calculate a period average population growth at the regional level and assume that the rate of growth of the sum of technological growth, $g$, and depreciation, $\delta$, is equal to 0.05 as is conventionally accepted in the literature on convergence.

Table 1 Summary statistics

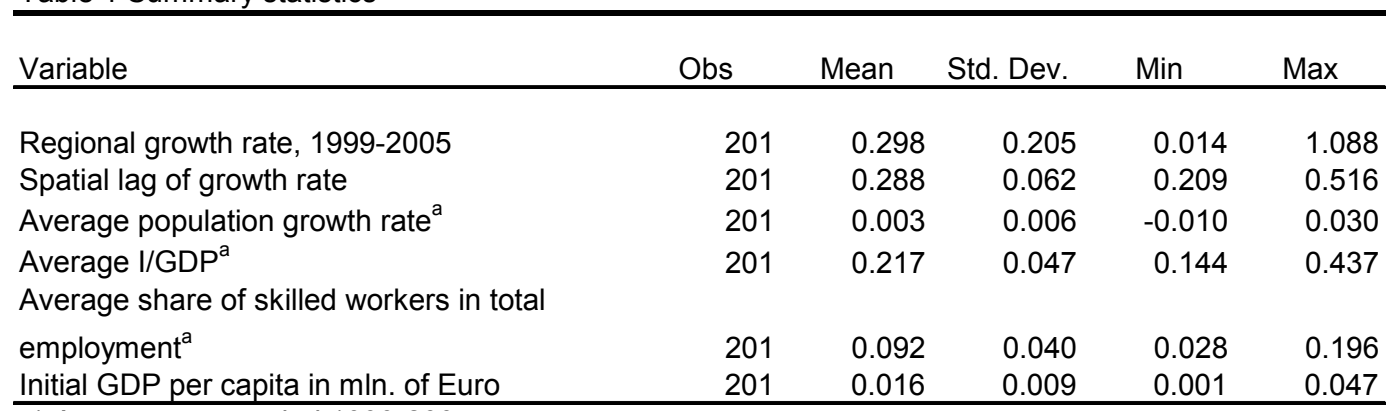

a) Average over period 1999-2005

Table 1 reports the summary statistics. Over the investigated period, the Bucuresti-Ilfov region (RO32 according to the NUTS 2 classification) experienced the highest growth of GDP per capita, which more then doubled between 1999 and 2005. In fact, all Romanian regions demonstrated very high growth rates during the investigated period, which can mainly be explained by very low initial values of GDP per capita and expected EU accession. Other Eastern European regions located in the Czech Republic, Hungary, Estonia, Latvia, Lithuania, and Slovakia were also among the top performers and experienced growth of more then 70 percent. The slowest growing regions, on the other hand, were three German regions (Berlin DE30, Lunenburg DE 93, and Köln DEA2), which grew by less then 5 percent during the same period.

Romanian regions that experienced the highest growth rates over the period 1999-2005 were also the poorest among all EU regions in 1999. Five out of the ten richest regions in 1999 were located in Germany, which grew at the slowest rate among all countries in the sample. Those observations point to an unconditional convergence, which is clearly illustrated by Figure 1. One

4 Employees with education level 5 or 6 according to the International Standard Classification of Education 1997 (ISCED). 
additional observation that can be inferred from Figure 1 is the possibility of convergence clubs with two distinct groups of countries: old EU members and new EU members.

Finally, it is not surprising that the fastest growing regions of the EU also have faster than average growing neighbors - the Romanian, Hungarian, and Slovak regions have the value of the spatial lag of GDP per capita growth higher then 40 percent. Figure 2 plots the graph of the spatial GDP per capita growth in 1999-2005 on GDP per capita growth over the same period, which gives a preliminary estimation of the unconditional, positive spatial dependence.

Figure 1 Unconditional convergence in 1999-2005

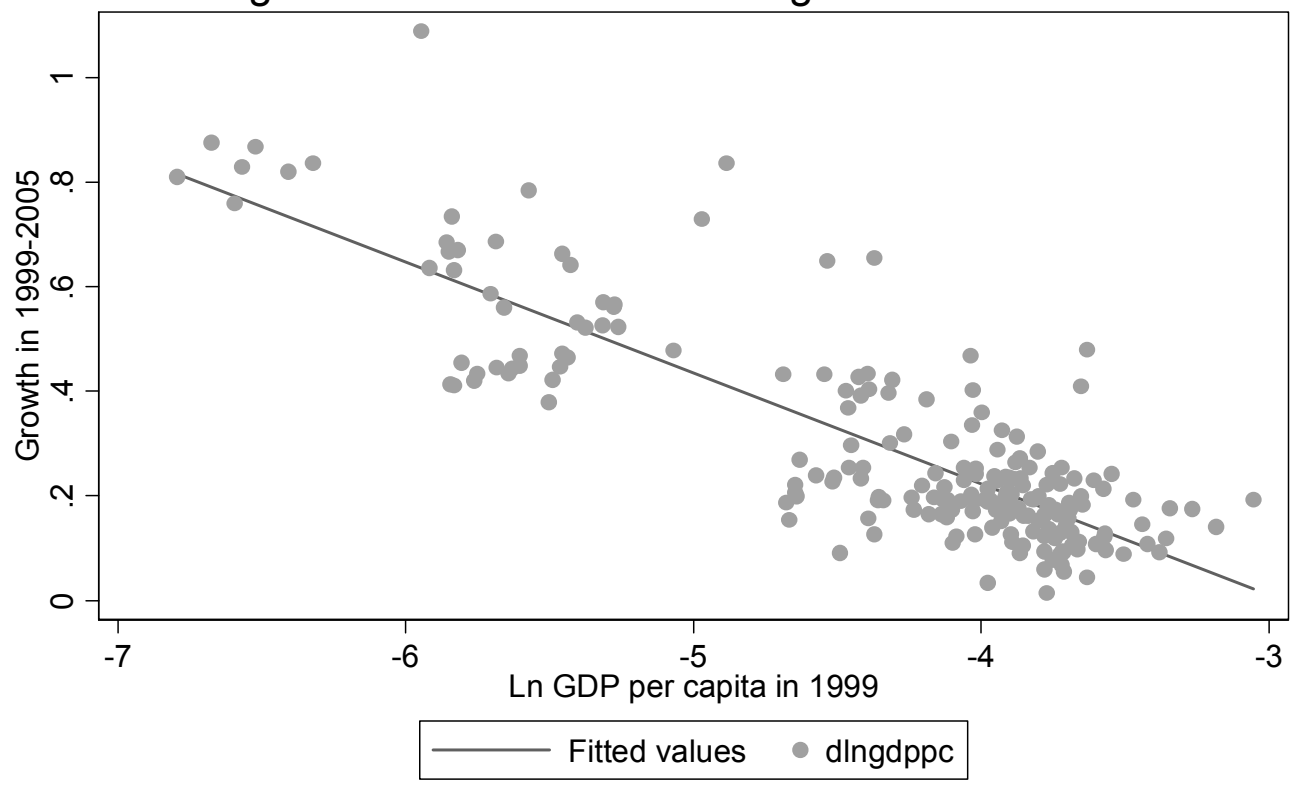


Figure 2 Unconditional spatial dependence

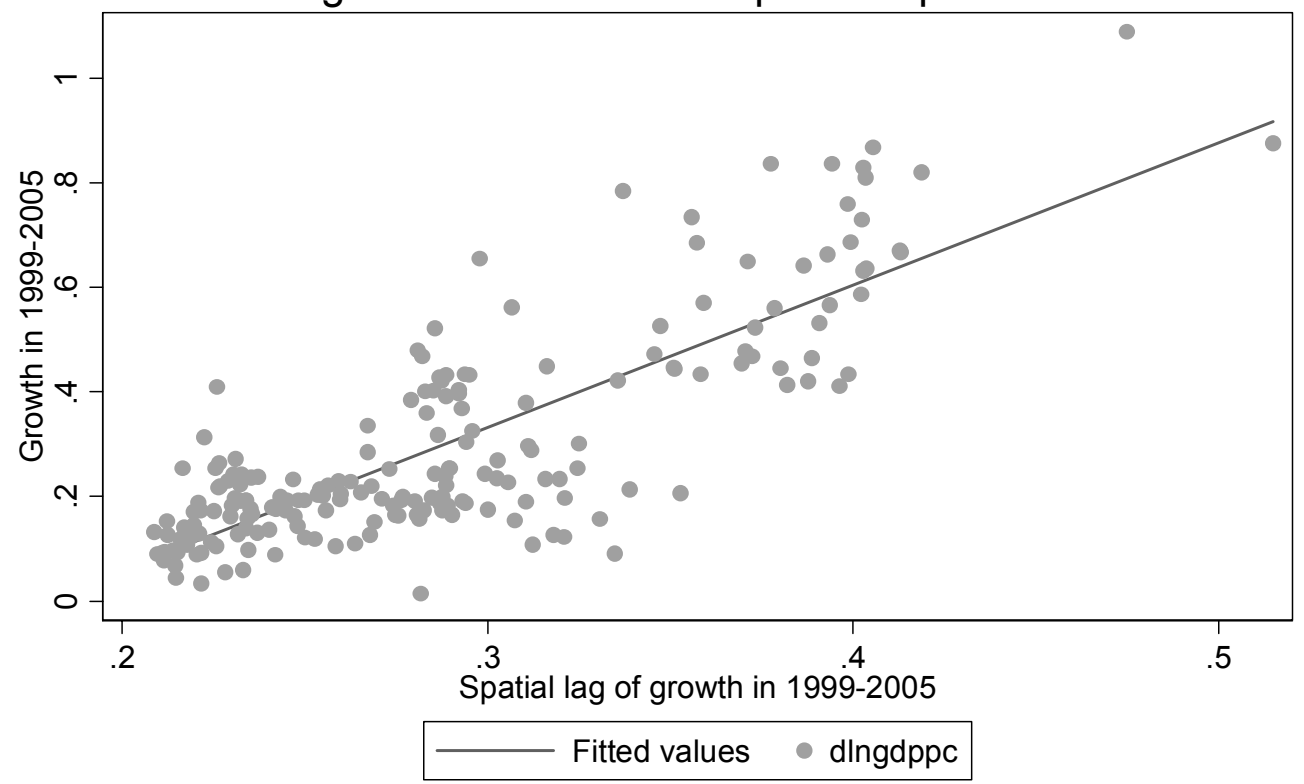

\subsection{Main Results and Discussion of Spatial Convergence}

Table 2 reports the baseline results and compares them with a Mankiw et al. (1992) type of regression presented in column (1). Column (2a) presents results of a standard spatial model with homoskedastic errors, while column (2b) presents HAC robust standard errors. Both models (1) and (2) look at the growth rate in GDP per capita in 1999-2005 for 201 regions for which we have data. The results confirm the initial hypothesis of convergence of the European regions that is indicated by the negative sign of ln GDP per capita in 1999. The spatial lag of growth of GDP per capita in model (2) is positive and significant at the 1 percent level. It is also economically large - an exogenous increase of growth in GDP per capita in the neighboring regions by 1 percent directly leads to a 0.6 percent increase in the GDP per capita in the observed region. Importantly, inclusion of the spatial lag of GDP per capita reduces in absolute value the coefficient associated with the convergence rate from 0.255 to 0.212 . Clearly, regression (1) is misspecified due to an omitted variable problem, and part of the convergence process comes from the spatial spillovers: a relatively poor region with a higher than average growth rate tends to be located close to other relatively poor regions with high growth rates. Other things being equal, when neighboring regions grow faster, it has a positive impact on the growth rates within the region itself.

For HAC estimation of the variance-covariance matrix presented in column (2b), I have chosen the Bartlett kernel function: 


$$
K\left(d^{*}, d_{i j}\right)=\left\{\begin{array}{c}
1-\frac{d_{i j}}{d^{*}\left(l_{n}\right)} \text { if } d_{i j}>d^{*}\left(l_{n}\right) \\
0 \text { otherwise }
\end{array}\right.
$$

and the bandwidth parameter $l_{n}=34 .{ }^{5}$ Correction for heteroskedaticity and spatial correlation of the error term presented in the third column of Table 2 is important because it substantially changes the estimates of the standard errors. For example, for the coefficient of the spatial lag of GDP per capita, it increases the standard error by 27 percent.

There are several other interesting findings that are worth mentioning. Unexpectedly, I found a positive impact of population growth on growth in GDP per capita. A closer look at population growth data revealed that Illes Baleares, Spain, was the fastest growing region with population growth at 3 percent per year on average. The second fastest growing region was Flevoland, Netherlands, with a population growth of 2.98 percent per year. Regions that grew faster than 2 percent per year included three other Spanish regions: Comunidad de Madrid, Comunidad Valenciana, and Region de Murcia.

${ }^{5}$ This value of the bandwidth parameter corresponds to $\tau=2 / 3$ and gives a more conservative estimation of the standard errors than discussed by Kelejian and Prucha (2007). 
Table 2 Main Results

\begin{tabular}{lcccc} 
Growth in GDP per capita in 1999-2005 & (1) OLS & \multicolumn{2}{c}{ (2) IV } & (3) FE \\
& & IV & IV HAC & \\
Ln (gdppc) in 1999 & $-0.255^{* * *}$ & $-0.212^{* * *}$ & $-.212^{* * *}$ & $-0.215^{* * *}$ \\
& $(0.011)$ & $(0.019)$ & $(0.022)$ & $(0.025)$ \\
Population growth & $0.214^{* *}$ & $0.220^{* *}$ & $.220^{* *}$ & 0.01 \\
& $(0.073)$ & $(0.070)$ & $(.082)$ & $(0.029)$ \\
S capital & 0.027 & 0.011 & .011 & 0.01 \\
& $(0.037)$ & $(0.036)$ & $(.057)$ & $(0.017)$ \\
S human capital & $0.111^{* * *}$ & $0.106^{* * *}$ & $.106^{* * *}$ & $0.038^{* *}$ \\
& $(0.017)$ & $(0.017)$ & $(.021)$ & $(0.015)$ \\
Spatial lag of growth in GDP per capita & & $0.638^{* *}$ & $0.638^{*}$ & $0.471^{* *}$ \\
& & $(0.234)$ & $(0.298)$ & $(0.146)$ \\
Constant & 0.136 & 0.117 & .117 & $-0.750^{* * *}$ \\
& $(0.192)$ & $(0.185)$ & $(.193)$ & $(0.125)$ \\
adjusted $\mathrm{R}^{2}$ & 0.768 & 0.786 & 0.786 & \\
$\mathrm{R}^{2}$ between & & & & 0.436 \\
$\mathrm{R}^{2}$ within & & & & 0.325 \\
$\mathrm{~N}$ & 201 & 201 & 201 & 885 \\
Standard errors in parentheses & & & & \\
${ }^{*} \mathrm{p}<0.05,{ }^{* *} \mathrm{p}<0.01,{ }^{* * *} \mathrm{p}<0.001$ & & & &
\end{tabular}

In addition, several regions of Ireland and Portugal experienced fast population growth. On the other hand, the three regions that experienced the fastest population decline were Sachsen-Anhalt, Chemnitz, and Thuringen from the former East Germany. Some regions of Latvia, Lithuania, Poland, and Romania also experienced a decline. These observations allow us to draw the following conclusion: the change in population can be associated with substantial migration flows from relatively poor and depressed regions of new EU members to those booming regions of old Europe that have more liberal migration laws.

The investment-to-GDP ration did not play an important role in GDP per capita growth during 1999-2005. Human capital, on the other hand, had a substantial positive contribution to economic growth. Regions that had a higher share of employees with a tertiary level of education tended to grow faster, which is consistent with the theory of a positive link between human capital accumulation and economic growth.

Unobserved regional heterogeneity in terms of climate, institutions, and state of technology can substantially bias my results. The above-mentioned factors are spatially correlated and can create an omitted variable bias that would invalidate the results. In order to check for this possibility, Table 2 also presents the results of the regression with regional fixed effects that capture region-specific factors, which either do not change over time (climate and absolute geographical location) or change relatively slowly (e.g., institutions). As can be seen from the 
last column of Table 2, the fixed effect regression gives a smaller, yet not statistically different, coefficient of the spatial lag of GDP per capita growth. However, it is important to notice that the fixed effect model, equation (3), looks at year-to-year changes in GDP per capita within a region, while the model equation (2) looks at convergence over a longer time horizon across regions, so the comparison across the models should be viewed with caution.

\subsection{Convergence in Wage per Employee}

In the previous section, I developed a model of convergence based on the Solow growth model. However, there are alternative theories that explain the geographical distribution of economic activities and can be directly linked to the model of economic growth. For example, the new economic geography literature (e.g., Krugman, 1991 ) links the endogenous location of firms and workers in an economy that has increasing returns at the firm's level and considerable trade costs. One of the predictions of this literature is proximity-concentration trade-off that leads to the development of core regions, which drive economic growth, create new technology, and attract the most productive workers, and periphery regions, which produce in traditional sectors such as agricultural products and natural resources. The core regions have higher productivity per worker and higher wages than the periphery regions. Because GDP per capita is not perfectly correlated with productivity per worker, I test the predictions of the new economic geography literature using wage per employee as the dependent variable and present the results in Table 3 . It shows that there is a convergence in wage per worker, but at considerably slower rates. The spatial spillovers, on the other hand, are much stronger. In addition, the importance of physical capital accumulation on economic growth is more pronounced, while human capital has no significant impact on the growth in wage per worker. 
Table 3 Wage per Employee

\begin{tabular}{lcccc} 
Growth in wage per worker in 1998-2004 & $\mathbf{( 1 )}$ OLS & \multicolumn{2}{c}{ (2) IV } & (3) FE \\
& & IV & IV HAC & \\
Ln (gdppc) in 1999 & $-0.155^{* * *}$ & $-0.098^{* * *}$ & $-0.098^{* * *}$ & $-0.071^{* * *}$ \\
& $(0.012)$ & $(0.013)$ & $(0.023)$ & $(0.019)$ \\
Population growth & $0.209^{* *}$ & $0.189^{* * *}$ & $0.189^{*}$ & -0.014 \\
& $(0.070)$ & $(0.054)$ & $(0.081)$ & $(0.029)$ \\
S capital & $0.196^{* * *}$ & $0.131^{* * *}$ & $0.131^{* *}$ & -0.026 \\
& $(0.040)$ & $(0.033)$ & $(0.043)$ & $(0.015)$ \\
S human capital & 0.030 & $0.028^{*}$ & 0.028 & 0.011 \\
& $(0.016)$ & $(0.013)$ & $(0.017)$ & $(0.007)$ \\
Spatial lag of Ln (gdppc) & & $1.250^{* * *}$ & $1.250^{* * *}$ & $1.293^{* * *}$ \\
& & $(0.203)$ & $(0.356)$ & $(0.169)$ \\
Constant & $1.656^{* * *}$ & $1.051^{* * *}$ & $1.051^{* * *}$ & 0.139 \\
& $(0.214)$ & $(0.194)$ & $(0.298)$ & $(0.103)$ \\
adjusted $\mathrm{R}^{2}$ & 0.671 & 0.800 & 0.800 & \\
$\mathrm{R}^{2}$ between & & & & 0.454 \\
$\mathrm{R}^{2}$ within & & & & 0.343 \\
$\mathrm{~N}$ & 172 & 172 & 172 & 873 \\
Standard errors in parentheses & & & & \\
* ${ }^{*}<0.05,{ }^{* *} \mathrm{p}<0.01,{ }^{* * *} \mathrm{p}<0.001$ & & & &
\end{tabular}

\subsection{Robustness Checks}

First, I present how changes of the kernel function $K(x)$ and bandwidth parameter $l_{n}$ impact our estimation of the standard errors of the coefficients in Table 4. It shows the standard errors of the estimated coefficients in the model for several values of the bandwidth $l_{n}$, which correspond to different values of $\tau$ and $d^{*}$. The fourth column of results is equivalent to the baseline model specification from Table 2. As a general rule, standard errors tend to increase with higher values of bandwidth, but are quite similar for different kernel functions. The Parzen kernel produces somewhat smaller standard errors, especially for higher values of the bandwidth parameters relative to results with Bartlett and TukeyHanning kernels. Importantly, the results presented in Table 2 do not change the significance at the 5 percent level, which indicates the robustness of the main results. 
Table 4 HAC Robust Standard Errors

(for different kernels and different levels of the bandwidth parameter)

\begin{tabular}{|c|c|c|c|c|c|}
\hline$\tau$ & 0.125 & 0.25 & 0.33 & 0.67 & 0.75 \\
\hline Bandwidth $I_{n}$ & 2 & 6 & 14 & 34 & 53 \\
\hline Distance, $\mathrm{d}^{*}\left(I_{n}\right)$, kilometers & 17 & 53 & 95 & 186 & 297 \\
\hline & \multicolumn{5}{|c|}{ Bartlett kernel } \\
\hline Spatial lag of growth rate & 0.252 & 0.256 & 0.262 & 0.299 & 0.313 \\
\hline Log of GDP per capita in 1999 & 0.018 & 0.018 & 0.018 & 0.022 & 0.025 \\
\hline Population growth & 0.070 & 0.070 & 0.071 & 0.082 & 0.093 \\
\hline S capitla & 0.045 & 0.045 & 0.046 & 0.057 & 0.071 \\
\hline \multirow[t]{2}{*}{ S human capital } & 0.017 & 0.017 & 0.017 & 0.020 & 0.025 \\
\hline & \multicolumn{5}{|c|}{ Parzen kernel } \\
\hline Spatial lag of growth rate & 0.252 & 0.255 & 0.258 & 0.274 & 0.305 \\
\hline Log of GDP per capita in 1999 & 0.018 & 0.018 & 0.018 & 0.019 & 0.023 \\
\hline Population growth & 0.070 & 0.070 & 0.071 & 0.076 & 0.085 \\
\hline S capitla & 0.045 & 0.045 & 0.045 & 0.050 & 0.061 \\
\hline \multirow[t]{2}{*}{ S human capital } & 0.017 & 0.017 & 0.017 & 0.018 & 0.021 \\
\hline & \multicolumn{5}{|c|}{ Tuckey-Hanning kernel } \\
\hline Spatial lag of growth rate & 0.252 & 0.257 & 0.261 & 0.292 & 0.323 \\
\hline Log of GDP per capita in 1999 & 0.018 & 0.018 & 0.018 & 0.021 & 0.025 \\
\hline Population growth & 0.070 & 0.070 & 0.071 & 0.081 & 0.092 \\
\hline S capitla & 0.045 & 0.045 & 0.045 & 0.056 & 0.069 \\
\hline$S$ human capital & 0.017 & 0.017 & 0.017 & 0.020 & \\
\hline
\end{tabular}

Second, I present how results change under different weighting matrix specifications. I consider a sequence of cutoff points $d^{\max }$ formulated as follows:

$$
\begin{aligned}
& \widetilde{d}_{i j}=d_{i j} \text { if } d_{i j} \leq d^{\max } \\
& \widetilde{d}_{i j}=\infty \text { if } d_{i j}>d^{\max }
\end{aligned}
$$

The weighting matrix is calculated as:

$$
\begin{aligned}
w_{i j} & =\frac{1 / \tilde{d}_{i j}}{\sum_{j=1, j \neq i}^{N} 1 / \tilde{d}_{i j}} \text { if } i \neq j \\
w_{i i} & =0
\end{aligned}
$$

The results presented in Table 5 are quite sensitive to the choice of the weighting matrix and show a nonlinear U-shaped relationship between the spatial 
lag of growth of GDP per capita and the cutoff distance. The HAC standard errors are calculated using the Bartlett kernel and the bandwidth parameter $l_{n}=34$, which gives the upper bound estimation of the standard errors.

\section{Table 5 Alternative Specifications of the Weighting Matrix}

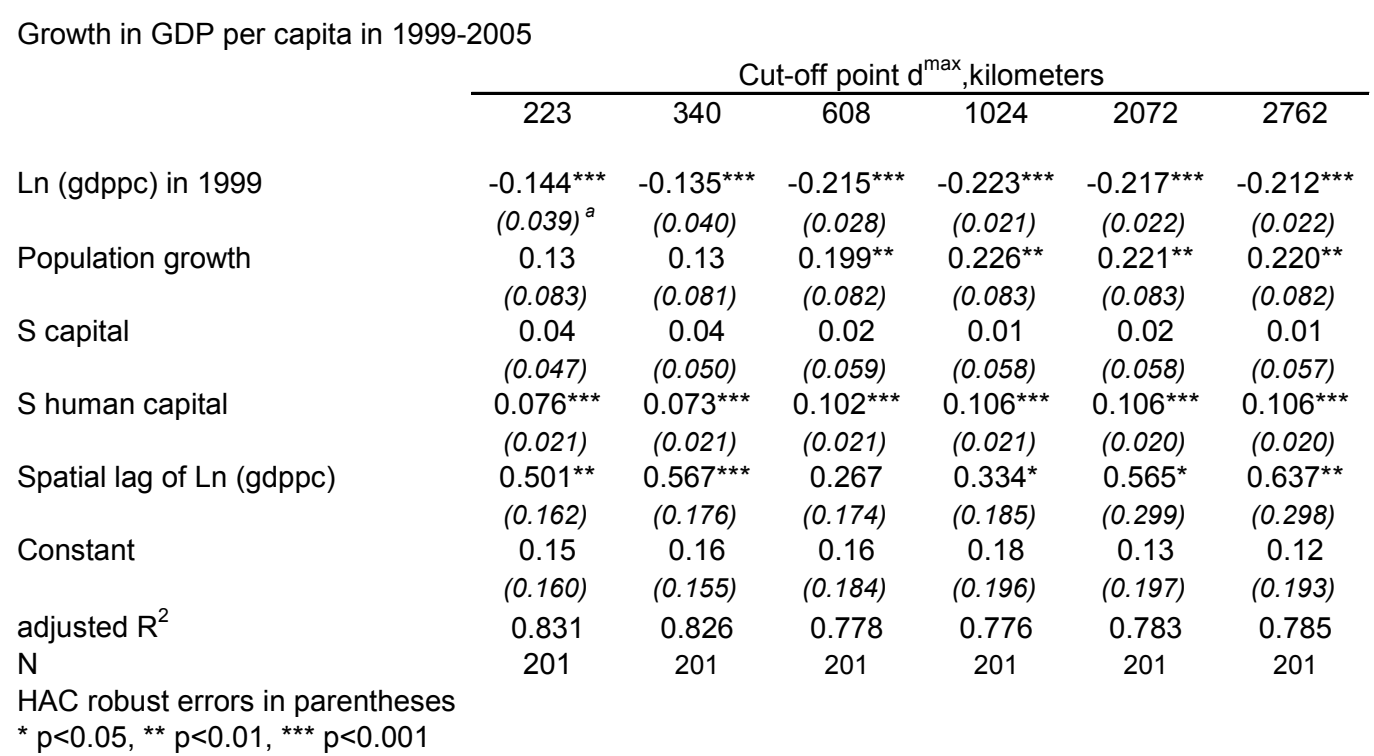

A U-shaped form of the coefficient of the spatial lag of growth rate as a function of cutoff points is additionally illustrated by Figure 3 for more values of $d_{\max }$. The results stabilize if we consider a cutoff point of 1,024 kilometers (636 miles) or higher. A possible explanation of such behavior may be an example of two forces working in opposite directions. On the one hand, very proximate regions located within 300 kilometers (186 miles) form an agglomeration with a center of economic life concentrated in a core city of a region that attracts human resources and firms and therefore reduces the attractiveness of other locations within the same agglomeration. On the other hand, big cities located farther from each other interact and benefit from trade and other forms of economic activities that strengthen positive spillovers over relatively remote trading partners. 
Figure 3 Coefficient of Global Spatial Spillovers

(as a function of the cutoff distance, $d_{\max }$ )

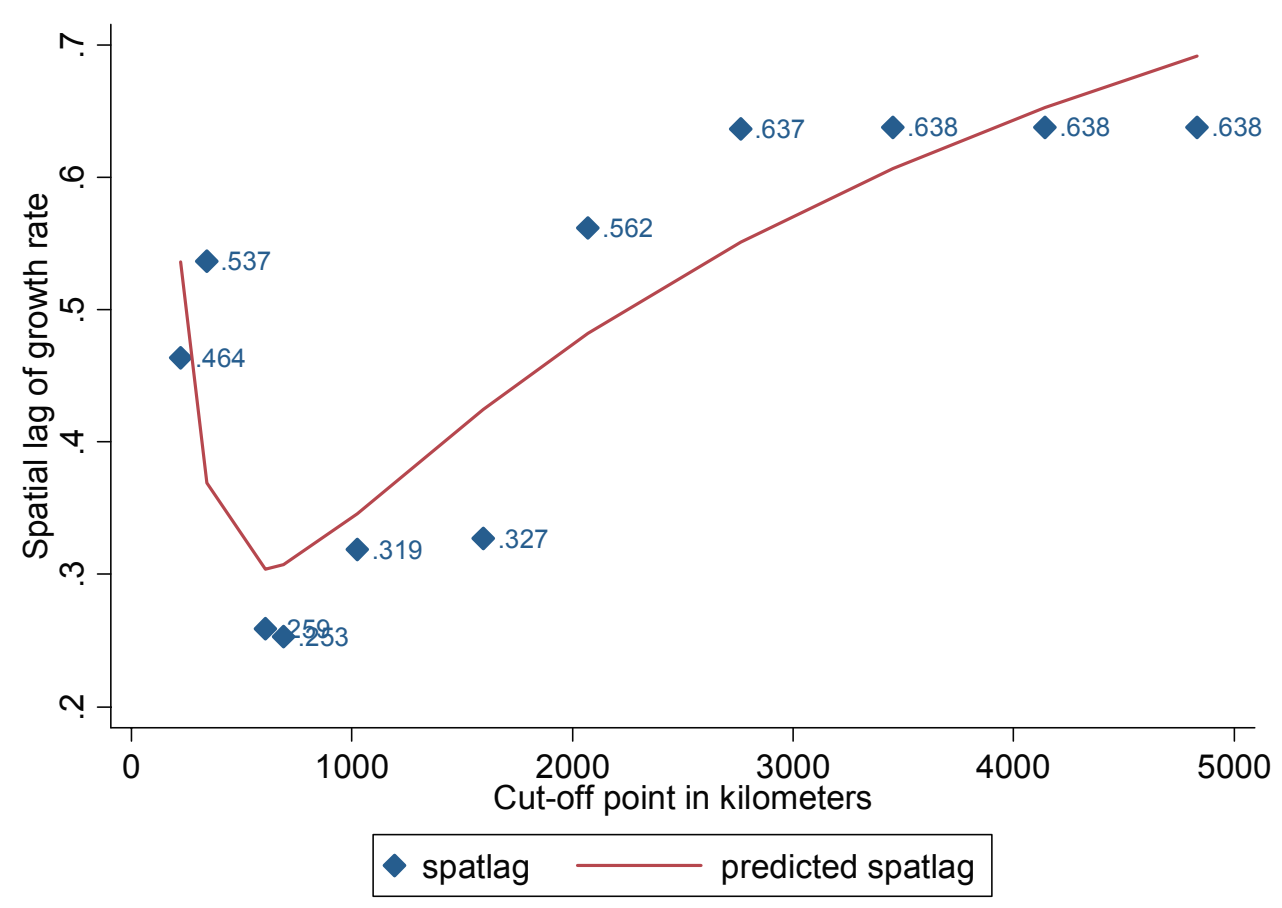

\section{$7 \quad$ Conclusions}

This paper applies a nonparametric heteroskedasticity and autocorrelation consistent (HAC) estimator of error terms in the context of the spatial autoregressive model of GDP per capita convergence of European regions at NUTS 2 level. By introducing the spatial dimension, it looks at how the equilibrium distribution of GDP per capita of EU regions evolves both in time and space dimensions. Results demonstrate that the global spatial spillovers of growth rates make an important contribution to the process of convergence by reinforcing the economic growth of neighboring regions. Poor regions that tend to locate closer to each other experience faster growth rates, which is consistent with the predictions of the Solow model. However, part of the faster economic growth comes not from local factors within the regions, but rather from the spatially reinforcing growth of neighboring regions. Results are even more pronounced when the convergence in wage per worker is considered.

Results demonstrate that correction for spatial heteroskedasticity and correlation is important because it takes into account unobserved spatial links and 
leads to significantly different estimation of the variance-covariance matrix. The choice of kernel functions does not significantly affect estimation of the variancecovariance matrix, while the choice of the bandwidth parameter is quite important. Finally, results are sensitive to the weighting matrix specification, and further research is needed to give a more rigorous justification for the selection of the weighting matrix.

\section{Appendix}

\section{Spatial 2SLS estimator}

From equation (5) and under the assumption that $|\rho|<1$, it can be shown that:

$$
\begin{aligned}
& W Y=W(I-\rho W)^{-1}(X \beta+u)=W \sum_{i=0}^{\infty}(\rho W)^{i}(X \beta+u) \\
& E(W Y \mid X)=W X \beta+\rho W^{2} X \beta+\ldots
\end{aligned}
$$

In addition,

$$
E\left(W^{i} X u\right)=0, i=0,1,2, \ldots
$$

Given the result (A1), optimal instruments for $Z=[X, W Y]$ are $E Z=[X, E(W y)]$. Consider the following subset of instruments, $H=\left[X, W X, W^{2} X\right]$. Let $\hat{Z}=P Z$, where $P=H\left(H^{\prime} H\right)^{-1} H^{\prime}$. The spatial 2SLS estimator has the following form:

$$
\hat{\delta}=\left(\hat{Z}^{\prime} Z\right)^{-1} \hat{Z}^{\prime} y
$$

\section{References}

Abreu, M., H. De Groot, and R. Florax, (2004) "Space and Growth: A Survey of Empirical Evidence Methods," Tinbergen Institute Working Paper No. TI 04-129/3, http://ssrn.com/abstract=631007.

Ades, A., and H. B. Chua, (1997) "Thy Neighbor's curse: regional instability and economic growth," Journal of Economic Growth, pp. 279-304.

Amiti, M., and B. Smarzynska Javorcik, (2008), "Trade costs and location of foreign firms in China," Journal of Development Economics, vol. 85 (12), pp. 129-149.

Anselin, L., (1988), Spatial Econometrics: Methods and Models, Boston: Kluwer. 
Andrews, D.W.K., (1991), "Heteroscedasticity and autocorrelation consistent covariance matrix estimation," Econometrica 59, pp. 817-858.

Arbia, G., R. Basile, and G. Piras, (2005), "Using Spatial Panel Data in Modelling Regional Growth and Convergence," ISAE Working Paper No. 55, http://ssrn.com/abstract $=936321$.

Barro, R., and X. Sala-i-Martin, (1992) "Convergence," The Journal of Political Economy, vol. 100, no. 2, pp. 223-251

Baumont, C., C. Ertur, and J. Le Gallo (2003), "Spatial Convergence Clubs and the European Regional Growth Process, 1980-1995," in: B. Fingleton (ed.), European Regional Growth, Springer, Berlin, pp. 131-158.

Bernard, A., and J. Bradford Jensen, (1999), "Exceptional Exporter Performance: Cause, Effect, or Both?" Journal of International Economics, 47 (1), pp. $1-25$.

De Long, J.B., and L.H. Summers, (1991), "Equipment Investment and Economic Growth," Quarterly Journal of Economics 106 (2), 445-502.

Durlauf, S.N., and D.T. Quah (1999), "The New Empirics of Economic Growth," in: J.B. Taylor and M. Woodford (eds.), Handbook of Macroeconomics, vol. 1A, North Holland, Amsterdam, pp. 235-308.

Fingleton, B., (2001), "Equilibrium and Economic Growth: Spatial Econometric Models and Simulations," Journal of Regional Science, 41 (February), pp. $117-147$.

Gallant, A. R., (1987), Nonlinear Statistical Models, New York: Wiley.

Garrett, T., G.A. Wagner, and D.C. Wheelock, (2005), "Regional Disparities in the Spatial Correlation of State Income Growth," FRB of St. Louis Working Paper No. 2005-061A, http://papers.ssrn.com/sol3/ papers.cfm?abstract $\mathrm{id}=840168$.

Head, K., and T. Mayer, (2004), "Market potential and the location of Japanese investment in the European Union," Review of Economics and Statistics 86 (4), pp. 959-972.

Helpman, E., M.J. Melitz, and S. R. Yeaple, (2004), "Export Versus FDI with Heterogeneous Firms," American Economic Review, 94 (1), pp. 300-16.

Kelijian, H., P. Murrell, O. Shepotylo, (2008), "Spatial Spillovers in the Development of Institutions," SSRN Working Paper, http://papers.ssrn.com/sol3/papers.cfm?abstract id $=1031974$

Kelejian, H., and I. Prucha, (1999), "A Generalized Moments Estimator for the Autoregressive Parameter in a Spatial Model," International Economic Review 40: pp. 509-533.

—, (2007), "HAC Estimation in a Spatial Framework," Journal of Econometrics, 140 (1), pp. 131-154.

Krugman, P., (1991), "Increasing Returns and Economic Geography," Journal of Political Economy 99 (3), pp. 483-499. 
Lambert, D., R. Florax, and Seong-Hoon Cho, (2008), "Bandwidth Selection For Spatial Hac And Other Robust Covariance Estimators," Working Papers 44258, Purdue University, Department of Agricultural Economics.

Le Gallo, Julie, (2004), "Space-Time Analysis of GDP Disparities among European Regions: A Markov Chains Approach," International Regional Science Review 27, pp. 138-163.

López-Bazo, E., E. Vayá, and M. Artís, (2004), "Regional Externalities and Growth: Evidence from European Regions," Journal of Regional Science 44, pp. 43-73.

Lucas, R., (1993), “Making a Miracle,” Econometrica 61 (March), pp. 251-271.

Mankiw, N., D. Romer, and D. Weil, (1992), "A Contribution to the Empirics of Economic Growth," The Quarterly Journal of Economics, vol. 107, no. 2, pp. 407-437.

Mittelhammer, R.C., G.G. Judge, and D.J. Miller, (2000), Econometric Foundations, Cambridge, Cambridge University Press.

Newey, W., and K. West, (1987), "A simple, positive semi-definite, heteroskedastic and autocorrelated consistent covariance matrix," Econometrica 55, pp. 703-708.

Rey, S.J., and M. Janikas, (2003), "Convergence in Space," Washington University, Economics Working Paper Archive at WUSTL, no. 0311002, Washington D.C.

Rey S. J., and B.D, Montuori, (1999), "US Regional Income Convergence: A Spatial Econometric Perspective," Regional Studies 33 (2), pp. 143-156. 